\title{
Global Innovations in Materials and Technologies for Energy Harvesting
}

\author{
Sivaraman Guruswamy, Joy A. Forsmark, and Robert Hyers
}

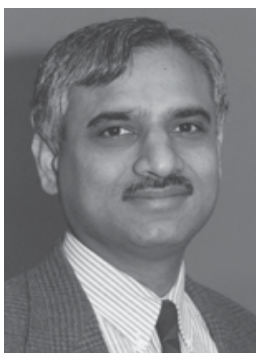

Sivaraman Guruswamy

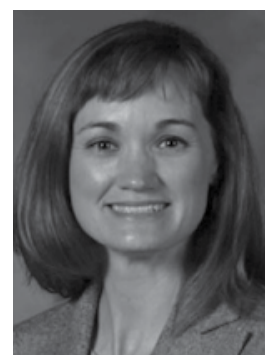

Joy A. Forsmark

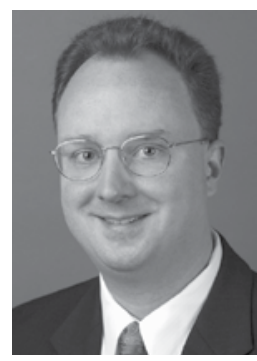

Robert Hyers ing from renewable energy sources and waste heat sources.

The symposia featured speakers who are leaders in academia, government, and industry. In this issue, three papers presented in the symposia are highlighted. In the first paper, Bhakta Rath, Associate Director of the Naval Research Laboratory, provides an overview of various energy resources of the Earth and technologies and materials issues involved in harvesting these energy resources, with special focus on energy derivable from the ocean.

In the second paper, Distinguished Professor Mildred Dresselhaus of the Massachusetts Institute of Technology and her collaborators examine the design of nanostructured bulk composite thermoelectric materials appropriate for devices used in large-scale waste energy harvesting from buildings, automobiles, and other waste heat sources, and in photovoltaic and thermophotovoltaic applications.

In the third paper, Jean-Pierre Fleurial of the NASA Jet Propulsion Laboratory examines novel advanced bulk thermoelectric materials and flexible lower-cost modular arrays capable of long-term operation at temperatures up to $1,300 \mathrm{~K}$ with more than $20 \%$ conversion efficiency for use in deep-space missions and terrestrial applications.

Three of the plenary talks presented but not included in this issue deal with photovoltaics, wind energy, and artificial photosynthesis. In his plenary talk "Solar Photovoltaics Technology: The Beginning of the Revolution," Larry Kazmeski, Director of the National
Photovoltaics Center at NREL, provided insights into the evolution of this technology. The presentation reviewed R\&D advances in cell design, materials, module options, the status and forecasts for next-generation PV systems based on organics, nanotechnologies, and non-conventional junction approaches. Shu-Ching Quek and Stephan Renou of GE Global Research discussed the combination of material development and process improvements needed for more efficient blades and cost-effective, lightweight, reliable larger megawatt class wind turbines that would allow expansion of wind sites to lower wind speed locations. Graham Fleming, of the University of California at Berkeley and Lawrence Berkeley National Laboratory, provided insight into the design principles responsible for the remarkable efficiency of natural photosynthetic light harvesting. A key invited paper by Takao Mori describes the development of boronrich p-type $\mathrm{REB}_{44} \mathrm{Si}_{2}$ and n-type RE-B$\mathrm{C}(\mathrm{N})$ cluster thermoelectric compounds exhibiting melting points above 2,200 $\mathrm{K}$ that his team has discovered. The invited presentation by N.B. Singh and coworkers from Northrop Grumman examined the effect of growth of $\mathrm{PbSe}$ nanocubes and nanodots with band gaps closely matched to the solar spectrum. Eight key contributed papers focused on recent photovoltaic and thermoelectric material developments were also featured in the symposia.

Sivaraman Guruswamy, Professor, is with the Department of Metallurgical Engineering, University of Utah, 135 South 1460 East, Room 412, Salt Lake City, UT 84112; Joy A. Forsmark, technical expert, is with Ford Motor Co., Dearborn, Ml 48121; and Robert Hyers, Associate Professor, is with the Mechanical Engineering Department, University of Massachusetts, Amherst, MA 01002. Dr. Guruswamy can be reached at s.guruswamy @utah.edu. 